\title{
Fósforo e enxofre disponível, alumínio trocável e fósforo remanescente em latossolo vermelho submetido ao gesso cultivado com trigo e soja
}

\author{
Available phosphorus and sulphur, exchangeable aluminum and \\ remaining phosphorus in rhodic eutrudox submitted to gypsum \\ cultivated with wheat and soybean
}

\author{
Leandro Rampim ${ }^{1 *}$; Maria do Carmo Lana ${ }^{2}$; Jucenei Fernando Frandoloso ${ }^{1}$
}

\section{Resumo}

A resposta ao gesso agrícola como fornecedor de nutrientes na subsuperfície proporciona melhor distribuição de raízes para culturas anuais e assim propicia às plantas explorar maior volume de solo aumentando a absorção de água e nutrientes e consequentemente incrementar a produtividade, com indícios da interferência do gesso no teor de fósforo disponível no solo. Neste trabalho o objetivo foi avaliar o uso do gesso agrícola $\left(\mathrm{CaSO}_{4} \cdot 2 \mathrm{H}_{2} \mathrm{O}\right)$ nos teores de fósforo e enxofre disponível, alumínio trocável e interferência no fósforo remanescente no solo nas profundidades de 0-0,10, 0,10-0,20 e 0,20$0,40 \mathrm{~m}$ em um Latossolo Vermelho eutroférrico de textura muito argilosa sob sistema de semeadura direta e produtividade das culturas de trigo e soja. Foi realizado coleta de amostras de solo aos seis e 12 meses após aplicação superficial de 1000, 2000, 3000, 4000 e $5000 \mathrm{~kg} \mathrm{ha}^{-1}$ de gesso e tratamento sem aplicação de gesso. $\mathrm{O}$ uso do gesso aumentou linearmente o teor de $\mathrm{S}$ disponível na profundidades de 0-0,10, 0,10-0,20 e 0,20-0,40 m, com teor mínimo de P disponível com a dose de $3166 \mathrm{~kg} \mathrm{ha}^{-1}$ e teor de mínimo $\mathrm{Al}$ trocável com a dose de $3300 \mathrm{~kg} \mathrm{ha}^{-1}$ na profundidade de $0,20-0,40 \mathrm{~m}$, no entanto, não influenciou os valores de $\mathrm{P}$ remanescente. $\mathrm{O}$ uso do gesso aumentou a produtividade de trigo, mas não influenciou a produtividade da soja.

Palavras-chave: Glycine Max, Triticum aestivum, sulfato, capacidade máxima de adsorção de fosfato, calagem

\begin{abstract}
The response to gypsum as a supplier of nutrients in the subsurface provides better root distribution for annual crops plants and thus provides use of larger volume of soil increasing the uptake of water and nutrients and therefore increased productivity, especially with evidence of interference of gypsum in phosphorus available in the soil. In this study evaluated the use of gypsum $\left(\mathrm{CaSO}_{4} \cdot 2 \mathrm{H}_{2} \mathrm{O}\right)$ the levels of available phosphorus and sulfur, exchangeable aluminum and interference in the remaining phosphorus in the soil at $0-0.10,0.10-0.20 ; 0.20-0.40 \mathrm{~m}$ of deep in Rhodic Eutrudox in no tillage and crop yields of wheat and soybean. It conducted sampling of soil at six and 12 months after surface application of $1000,2000,3000,4000$ and $5000 \mathrm{~kg} \mathrm{ha}^{-1}$ gypsum and treatment without application of gypsum. The use of gypsum increased linearly the $\mathrm{S}$ content available at depths of $0-0.10,0.10-0.20$ and $0.20-0.40$ $\mathrm{m}$, minimum $\mathrm{P}$ content available at the dose of $3166 \mathrm{~kg} \mathrm{ha}^{-1}$ and exchangeable $\mathrm{Al}$ minimum point at the
\end{abstract}

\footnotetext{
${ }^{1}$ Doutorandos em Agronomia, Produção Vegetal, Universidade Estadual do Oeste do Paraná, UNIOESTE, Centro de Ciências Agrárias, campus Marechal Cândido Rondon, Marechal Cândido Rondon, PR. E-mail: rampimleandro@yahoo.com.br; neiff@, bol.com.br

${ }^{2}$ Prof ${ }^{\mathrm{a}}$ Associado-B, UNIOESTE, Marechal Cândido Rondon, PR. E-mail: maria.lana@unioeste.br

*Autor para correspondência
} 
dose of $3300 \mathrm{~kg} \mathrm{ha}^{-1}$ at a depth of $0.20-0.40 \mathrm{~m}$ however, did not affect the remaining P values. The use of gypsum increased the productivity of wheat, but did not influence soybean yield.

Key words: Glycine max, Triticum aestivum, sulfate, maximum adsorption capacity of phosphate, liming

\section{Introdução}

A produção nacional do trigo para a safra 2011/12 estimada em aproximadamente de 5,15 milhões de toneladas (CONAB, 2011), porém, tal produção supre apenas 50\% do consumo brasileiro. Por outro lado, a produção de soja colhida na safra 2010/2011 foi 75,32 milhões de toneladas, mantendo o ritmo de crescimento das últimas safras (CONAB, 2011), com exportação de 32,4 milhões de toneladas e consumo interno de 36,2 milhões de toneladas de soja previsto para a safra 2011/12 (ABIOVE, 2011). Desta forma, há crescente demanda por insumos e principalmente fertilizantes para manter o crescimento em produtividade das culturas e para suprir a demanda mundial de produtos agrícolas, visto que, segundo Araújo et al. (2008), os solos brasileiros apresentam deficiência em fósforo e que os fosfatos são recursos naturais não renováveis. Conforme Quevedo e Paganini (2011) a velocidade de exploração de jazidas de fosfato pode atingir colapso nas fontes disponíveis e conhecidas, com impactos econômicos, sociais e ambientais graves e irreversíveis.

O gesso agrícola é basicamente sulfato de cálcio dihidratado $\left(\mathrm{CaSO}_{4} \cdot 2 \mathrm{H}_{2} \mathrm{O}\right)$. Na produção de ácido fosfórico as indústrias de fertilizantes utilizam como matéria prima a rocha fosfática (apatita), que ao ser atacada por ácido sulfúrico + água, produz como subproduto da reação o sulfato de cálcio e ácido fluorídrico. A composição química média do gesso agrícola obtida é: S (17,7\%), $\mathrm{CaO}(30,9 \%), \mathrm{F}$ $(0,2 \%)$ e $\mathrm{P}_{2} \mathrm{O}_{5}(0,7 \%)$ (DIAS, 1992).

Uma vez na solução do solo, o íon $\mathrm{Ca}^{2+}$ oriundo do gesso pode reagir no complexo de troca do solo, deslocando $\mathrm{Al}^{3+}, \mathrm{K}^{+}, \mathrm{Mg}^{2+}$, para a solução do solo, que podem, por sua vez, reagir com o $\mathrm{SO}_{4}{ }^{2-}$ formando $\mathrm{AlSO}_{4}^{+}$(que é menos tóxico para as plantas) e os pares iônicos neutros: $\mathrm{K}_{2} \mathrm{SO}_{4}{ }^{0}$ e $\mathrm{MgSO}_{4}{ }^{0}$, além do $\mathrm{CaSO}_{4}{ }^{0}$, os quais apresentam grande mobilidade no perfil (PAVAN; BINGHAM; PRATT, 1984).

O gesso, um mineral de ocorrência abundante, tem sido usado como condicionador de solos ácidos e solos argilosos e como suprimento de nutrientes (QUAGGIO et al.,1993; SILVA; RAIJ; CARVALHO, 1997; CAIRES et al., 2002; NOGUEIRA; MELO, 2003; VITTI et al., 2008; NEIS et al., 2010), reduzindo a saturação de alumínio (ROTH et al., 1986; VITTI et al., 2008), modificando as características químicas do solo para o crescimento de plantas (SOUZA et al., 2010), agente descompactante do solo (RAIJ, 2008) e com isto proporciona condições para aumentar a absorção de nutrientes e água (SOUZA; LOBATO; REIN, 1996) e elevar a produtividade de grãos (RAIJ et al., 1994; SOUZA; LOBATO; REIN, 1996; CAIRES et al., 2002, SORATTO; CRUSCIOL, 2008, SORATTO et al., 2010). Desta forma, a utilização de gesso permite evitar a interrupção do sistema plantio direto, uma vez que não há mais revolvimento do solo nesse sistema de cultivo, após sua implantação.

Contudo, em alguns casos, o efeito negativo da acidez do solo e da toxidez por $\mathrm{Al}^{+3}$ na produção agrícola não tem sido observado em sistema de plantio direto (SPD), havendo ausência de resposta das culturas tanto à calagem (ALLEONI; CAMBRI; CAIRES, 2005; CAIRES et al., 2006) como ao gesso (SILVA; NOVAIS; SEDIYAMA, 1984), demonstrado por (ZAMBROSI; ALLEONI; CAIRES, 2007), os quais determinaram a 
especiação iônica do alumínio no solo, mostrando que $68,7 \%$ do Al trocável está ligado ao carbono orgânico disponível, 29,4\% ligado ao ânion flúor e $0,1 \%$ ligado ao sulfato na profundidade de $0-0,05$ m, e $33,5 \%$ do Al trocável está ligado ao carbono orgânico disponível e 66,1\% ligado ao ânion flúor na profundidade de $0,20-0,40 \mathrm{~m}$, contudo com a utilização de $6000 \mathrm{~kg} \mathrm{ha}^{-1}$ de gesso $74,5 \%$ do Al trocável está ligado ao carbono orgânico disponível, $20,5 \%$ ligado ao ânion flúor e 0,2\% ligado ao sulfato na profundidade de $0-0,05 \mathrm{~m}$ e $14,1 \%$ do Al trocável está ligado ao carbono orgânico disponível e 85,8\% ligado ao ânion flúor na profundidade de 0,20-0,40 m. De forma que a redução da toxicidade do Al encontrada no SPD nas camadas superficiais podem estar associadas com a sua complexação com ácidos orgânicos, formando complexos com o carbono orgânico dissolvido (FRANCHINI et al., 2001, 2003; ZAMBROSI; ALLEONI; CAIRES, 2007).

Em experimento realizado por Caires et al. (2003), o uso do gesso proporcionou alterações nas reações químicas do subsolo, aumentando o $\mathrm{pH}$ $\left(\mathrm{CaCl}_{2}\right.$ 0,01 $\left.\mathrm{mol} \mathrm{L}^{-1}\right)$, os teores de $\mathrm{Ca}$ e $\mathrm{S}_{-} \mathrm{SO}_{4}{ }^{2-} \mathrm{e}$ aumentou a concentração de $\mathrm{P}$ na camada superficial do solo (0-0,05 m). Para Zambrosi, Alleoni e Caires (2007), a adição de gesso incrementou a percentagem de fósforo ligado à alumínio no solo, passando de $18,6 \%$ na testemunha para $59,8 \%$ com $3000 \mathrm{~kg} \mathrm{ha}^{-1}$ de gesso, ao passo que a forma química predominante de sulfato no solo, mesmo com acréscimo de gesso, está em torno de $90 \%$ na forma de $\mathrm{SO}_{4}^{-2}$. Segundo Bilibio, Corrêa e Borges (2010) pode ocorrer alterações nos atributos químicos com a utilização de diferentes sistemas de manejo, assim como com a utilização de calcário e gesso, principalmente em relação aos elementos $\mathrm{P}, \mathrm{Ca}$ e K.

Em estudos realizados por Broggi et al. (2010), as características dos solos que melhor se correlacionaram com a taxa de recuperação do $\mathrm{P}$ aplicado, foram o $\mathrm{P}$ remanescente (P-rem) e a capacidade máxima de adsorção de fósforo (CMAP) e que os solos com maior CMAP e menor P-rem apresentaram reversibilidade maior do $\mathrm{P}$ não lábil ( $\mathrm{P}$ residual) em intervalo menor de tempo. Vilar et al. (2010) também detectaram correlação significativa do P-rem com a capacidade máxima de adsorção de $\mathrm{P}$ da fração argila, mostrando que com o aumento do P-rem ocorre redução na capacidade máxima de adsorção de $\mathrm{P}$.

O P-rem, descrito como a quantidade do $\mathrm{P}$ adicionado que fica na solução de equilíbrio após definido tempo de contato com o solo; ao apresentar estreita correlação com a capacidade tampão, e a CMAP e capacidade máxima de adsorção de sulfatos (CMAS) permite definir as doses de P e/ou S necessária para determinações físico-químicas, fato que com P-rem de 0-4 mg L${ }^{-1}$ corresponde a doses de 200-260 $\mathrm{mg} \mathrm{L}^{-1}$ de P para determinar a CMAP e 40-52 $\mathrm{mg} \mathrm{L}^{-1}$ de $\mathrm{S}$ para determinar a CMAS, assim como P-rem dose de 44-60 $\mathrm{mg} \mathrm{L}^{-1}$ corresponde a dose de 0-60 $\mathrm{mg} \mathrm{L}^{-1}$ de $\mathrm{P}$ para determinar a CMAP e de 0-12 $\mathrm{mg} \mathrm{L}^{-1}$ de $\mathrm{S}$ para determinar a CMAS. O P-rem também pode ser utilizado para estimar o nível crítico de $\mathrm{P}$ disponível e a declividade do $\mathrm{P}$ disponível como função do $\mathrm{P}$ adicionado ao solo.

A necessidade de gesso na camada subsuperficial com $0,20 \mathrm{~m}$ de espessura pode ser estimada em função do valor de P-rem, de acordo com a equação: $\mathrm{NG}=1,684-0,136168 \mathrm{P}-$ rem $^{0,5}-0,304166 \mathrm{P}-$ rem + 0,002588 P-rem ${ }^{1,5} \mathrm{R}^{2}=0,9994$ (ALVAREZ V. et al., 2000). Destaca-se que o sulfato adsorvido no solo é deslocado pelo fosfato, visto que o sulfato é retido com menor energia de adsorção que o fosfato numa ampla faixa de $\mathrm{pH}$ (HSU, 1989) e que o aniôn que pode deslocar o $\mathrm{P}$ da fase sólida do solo com maior eficiência é o silicato e em segundo lugar, vem o sulfato (NOVAIS et al., 2007). Contudo, ao utilizar a recomendação de gesso pela metodologia de Alvarez et al. (2000) também é necessário conhecer o histórico de aplicações de gesso.

Desta forma, é importante verificar os efeitos da utilização de gesso na disponibilidade de $\mathrm{P}$ disponível e no valor de P-rem no solo. Neste 
trabalho o objetivo foi avaliar o uso do gesso agrícola $\left(\mathrm{CaSO}_{4} \cdot 2 \mathrm{H}_{2} \mathrm{O}\right)$ nos teores de fósforo e enxofre disponível, alumínio trocável e interferência no valor do fósforo remanescente no solo nas profundidades de $0-0,10,0,10-0,20$ e $0,20-0,40 \mathrm{~m}$ em um Latossolo Vermelho eutroférrico de textura muito argilosa sob sistema de semeadura direta e produtividade das culturas de trigo e soja.

\section{Material e Métodos}

O experimento foi realizado no município de Guaíra, PR, com Latitude: $24^{\circ} 09^{\prime} 12^{\prime \prime}$ e e Longitude: $54^{\circ} 12^{\prime} 23^{\prime}$ W. A área é utilizada em sistema de semeadura direta há 15 anos em sucessão de culturas, utilizando soja no verão e trigo/milho no inverno, em solo classificado como Latossolo Vermelho eutroférrico de textura muito argilosa (EMBRAPA, 2006), com $800 \mathrm{~g} \mathrm{~kg}^{-1}$ de argila, $145 \mathrm{~g} \mathrm{~kg}^{-1}$ de silte e $55 \mathrm{~g} \mathrm{~kg}^{-1}$ de areia obtido pelo método do densímetro (EMBRAPA, 1997), média fertilidade com baixa concentração de $\mathrm{Al}^{+3}$, cuja caracterização química anterior à aplicação dos tratamentos consta na Tabela 1.

Seis meses antes da instalação do experimento, no dia primeiro de outubro de 2005 , foi realizada calagem superficial com aplicação de $1650 \mathrm{~kg} \mathrm{ha}^{-1}$ de calcário calcítico com PRNT (Poder relativo de neutralização total) de $70 \%$, seguida de subsolagem profunda, em função da presença de adensamento na camada entre $0,15-0,30 \mathrm{~m}$ no solo, e posterior cultivo da soja.

Tabela 1. Resultado da análise química da área experimental, nas profundidades de $0-0,10,0,10-0,20$ e $0,20-0,40 \mathrm{~m}$, a partir da coleta de solo realizada em março de 2006, em Latossolo Vermelho eutroférrico de textura argilosa.

\begin{tabular}{|c|c|c|c|c|}
\hline \multirow{2}{*}{ Característica } & \multirow{2}{*}{ Unidade } & \multicolumn{3}{|c|}{ Profundidade } \\
\hline & & $0-0,10 \mathrm{~m}$ & $0,10-0,20 \mathrm{~m}$ & $0,20-0,40 \mathrm{~m}$ \\
\hline $\mathrm{pH}^{(1)}$ & & 4,8 & 4,1 & 4,1 \\
\hline $\mathrm{Al}^{(2)}$ & $\mathrm{cmol}_{\mathrm{c}} \mathrm{dm}^{-3}$ & 0,20 & 0,35 & 0,45 \\
\hline $\mathrm{H}+\mathrm{Al}^{(3)}$ & $\mathrm{cmol}^{\mathrm{c}} \mathrm{dm}^{-3}$ & 4,61 & 4,28 & 4,96 \\
\hline $\mathrm{Ca}^{(2)}$ & $\mathrm{cmol}_{\mathrm{c}}^{\mathrm{c}} \mathrm{dm}^{-3}$ & 4,77 & 4,04 & 3,77 \\
\hline $\mathrm{Mg}^{(2)}$ & $\mathrm{cmol} \mathrm{dm}^{-3}$ & 1,98 & 1,85 & 1,60 \\
\hline $\mathrm{K}^{(4)}$ & $\mathrm{cmol}_{\mathrm{c}}^{\mathrm{c}} \mathrm{dm}^{-3}$ & 0,59 & 0,35 & 0,26 \\
\hline SB & $\mathrm{cmol}^{\mathrm{c}} \mathrm{dm}^{-3}$ & 7,34 & 6,24 & 5,63 \\
\hline CTC & $\mathrm{cmol}_{\mathrm{c}}^{\mathrm{c}} \mathrm{dm}^{-3}$ & 11,95 & 10,52 & 10,59 \\
\hline $\mathrm{V}$ & c & 61,42 & 59,32 & 53,16 \\
\hline $\mathrm{m}$ & $\%$ & 2,65 & 5,31 & 7,40 \\
\hline $\mathrm{P}^{(4)}$ & $\mathrm{mg} \mathrm{dm}^{-3}$ & 12,32 & 7,19 & 3,11 \\
\hline $\mathrm{S}-\mathrm{SO}_{4}{ }^{(5)}$ & $\mathrm{mg} \mathrm{dm}{ }^{-3}$ & 11,43 & 18,5 & 21,49 \\
\hline $\mathrm{MO}^{4}$ & $\mathrm{~g} \mathrm{dm}^{-3}$ & 19,82 & 15,04 & 10,94 \\
\hline
\end{tabular}

${ }^{(1)} \mathrm{pH}$ em $\mathrm{CaCl}_{2}$, relação 1:2,5. ${ }^{(2)}$ Extrator $\mathrm{KCl} 1 \mathrm{~mol} \mathrm{~L}^{-1} \cdot{ }^{(3)}$ Extrator acetato de cálcio 0,5 $\mathrm{mol} \mathrm{L}^{-1} \mathrm{pH} 7,0 .{ }^{(4)}$ Extrator Mehlich ${ }^{-1}$. ${ }^{(5)}$ Extrator $\mathrm{Ca}\left(\mathrm{H}_{2} \mathrm{PO}_{4}\right)_{2} 500 \mathrm{mg} \mathrm{L}^{-1}$ de P em HOAc $2 \mathrm{~mol} \mathrm{~L}^{-1}$ (EMBRAPA, 1999).

Fonte: Elaboração dos autores.

O experimento foi instalado em abril de 2006 em delineamento de blocos casualizados com seis repetições. Foram utilizadas doses crescentes 1000, 2000, 3000, 4000, $5000 \mathrm{~kg} \mathrm{ha}^{-1}$ de gesso agrícola (17\% de $\mathrm{Ca}, 15 \%$ de $\mathrm{S})$ e tratamento sem a aplicação de gesso agrícola, totalizando 36 parcelas experimentais.

A instalação do experimento foi realizada sobre a palhada oriunda da cultura da soja. A aplicação do gesso em superfície foi realizada em abril de 2006, 
portanto, seis meses após a aplicação de calcário. As parcelas avaliadas tinham área total de 12,00 $\mathrm{m}^{2}$, com área útil de $5,92 \mathrm{~m}^{2}$ para a cultura de trigo e $5,40 \mathrm{~m}^{2}$ para a cultura da soja. A precipitação pluvial mensal no período de abril de 2006 e março de 2007, durante a condução do experimento, foi $1535 \mathrm{~mm}$ (Figura 1).

Figura 1. Precipitação pluvial mensal no período da experimentação a campo, entre abril de 2006 e março de 2007 e precipitação média mensal de 1973 a 2009 medidos na estação meteorológica de Palotina/PR.

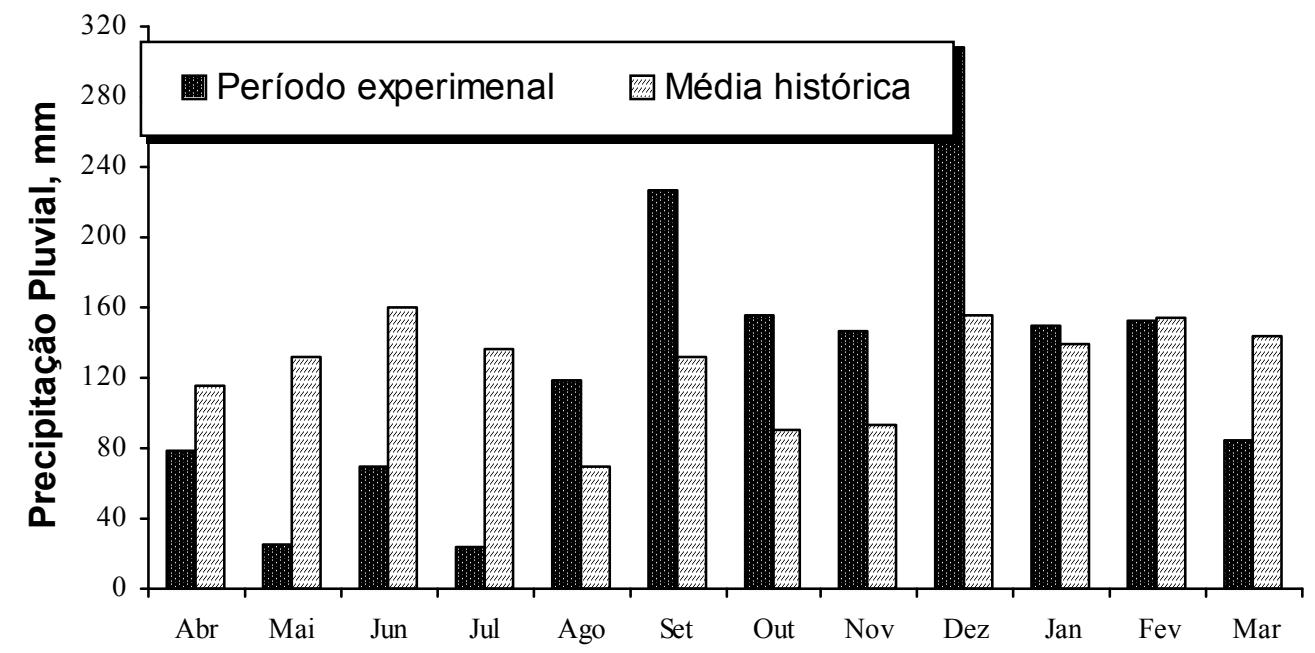

Fonte: Elaboração dos autores.

Durante o período de realização do experimento efetuou-se inicialmente o cultivo de trigo, com espaçamento de $0,17 \mathrm{~m}$ e densidade de 68 sementes por metro de sulco, com a variedade CD 104, classificada como moderadamente sensível à presença de alumínio trocável. E em seguida realizou-se o cultivo da soja, com espaçamento de 0,45 m e densidade de 18 sementes por metro de sulco, com a variedade transgênica CD 214RR, caracterizada como tolerante ao alumínio trocável.

As coletas das amostras de solos foram efetuadas em outubro de 2006 e abril de 2007. Após cada cultivo, foram retiradas em cada parcela na entrelinha da cultura três amostras simples com trado, para compor uma amostra composta de solo nas profundidades de $0-0,10,0,10-0,20$ e 0,20 $0,40 \mathrm{~m}$, para avaliar os teores no solo de enxofre disponível ( $\left.\mathrm{S}_{-} \mathrm{SO}_{4}\right), \mathrm{P}$ disponível por Mehlich-1 (P) e Al trocável $\left(\mathrm{Al}^{+3}\right)$ segundo Embrapa (1999) e fósforo remanescente (P-rem) (ALVAREZ V. et al., 2000). Foi avaliada a produtividade das culturas, de forma que foi realizada a colheita da parte aérea das plantas da cultura de trigo em 15 de setembro de 2006 e da soja em três de março de 2007, trilhandoas em Trilhadeira Vencedora B-150 para a obtenção dos grãos, os quais foram levados à balança de precisão para a determinação da produtividade, com posterior padronização da umidade das amostras, para $13 \%$ de umidade na cultura de trigo e $14 \%$ na soja.

Os dados obtidos foram submetidos à análise de variância e de regressão utilizando o programa SAEG 8.0 (1999). Os modelos que melhor se ajustaram aos dados foram escolhidos com base na significância pelo teste $\mathrm{F}$, considerando os níveis de 5 e $1 \%$ de probabilidade e no maior valor do coeficiente de determinação. 


\section{Resultados e Discussão}

\section{Alumínio trocável}

A presença de Al trocável em solos de regiões tropicais úmidas é oriunda da acidificação do solo e deve-se à substituição de cátions trocáveis por íons
$\mathrm{H}^{+}$e $\mathrm{Al}^{3+}$, absorção de cátions básicos pelas plantas e uso de fertilizantes de caráter ácido. Com o incremento das doses de gesso, inicialmente ocorre redução de $\mathrm{Al}^{+3}$ e P nas camadas no solo (Figura 2a, $2 b, 2 c$ e $2 d)$.

Figura 2. Teor de Al trocável aos seis (a) e doze meses (b), teor de P disponível aos seis (c) e doze meses (d) e P remanescente aos seis (e) e doze meses (f) no Latossolo Vermelho Escuro eutroférrico da área experimental, na camada de 0-0,10 m, 0,10-0,20 m e 0,20-0,40 m de profundidade após a aplicação de doses de gesso agrícola. * e ** significativos a 5 e $1 \%$ pelo teste $\mathrm{F}$.

6 meses

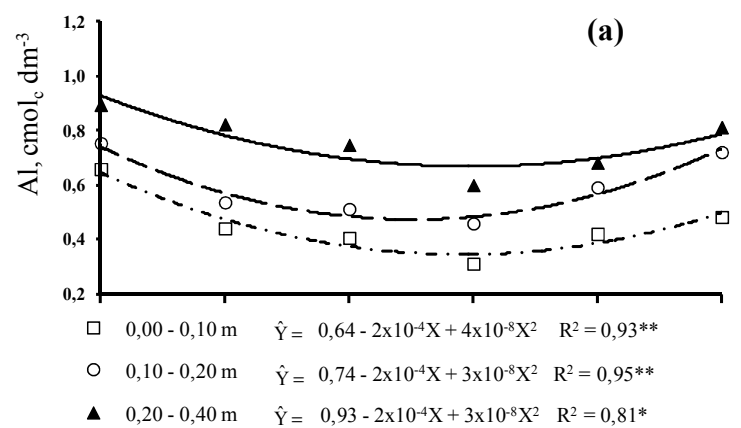

(c)

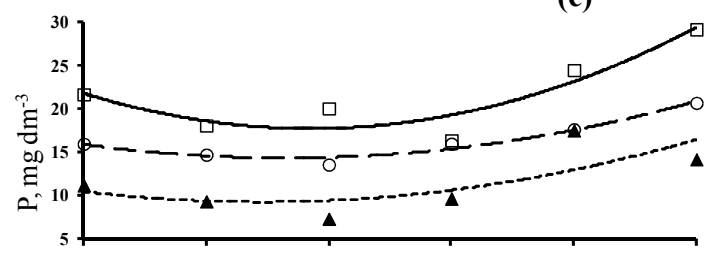

$0,00-0,10 \mathrm{~m} \quad \mathrm{y}=21,677-0,0044 \mathrm{x}+1 \times 10^{-6} \mathrm{X}^{2} \mathrm{R}^{2}=0,8539^{*}$ ○ $0,10-0,20 m \quad y=15,879-0,0019 X+1 \times 10^{-7} X^{2} R^{2}=0,9649^{* *}$ \ $0,20-0,40 m \quad y=10,434-0,0017 X+6 \times 10-7 X 2 R 2=0,5394^{* *}$

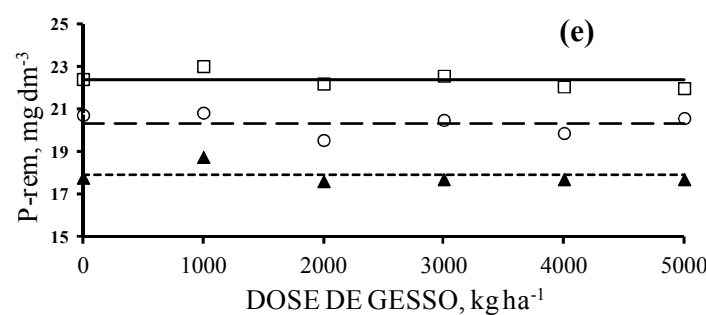

ㅁ $0,00-0,10 \mathrm{~m} \quad \hat{\mathrm{Y}}=\overline{\mathrm{Y}}=22,38$

○ $0,10-0,20 \mathrm{~m} \quad \hat{\mathrm{Y}}=\overline{\mathrm{Y}}=20,34$

A $0,20-0,40 \mathrm{~m} \quad \hat{\mathrm{Y}}=\overline{\mathrm{Y}}=17,87$
12 meses

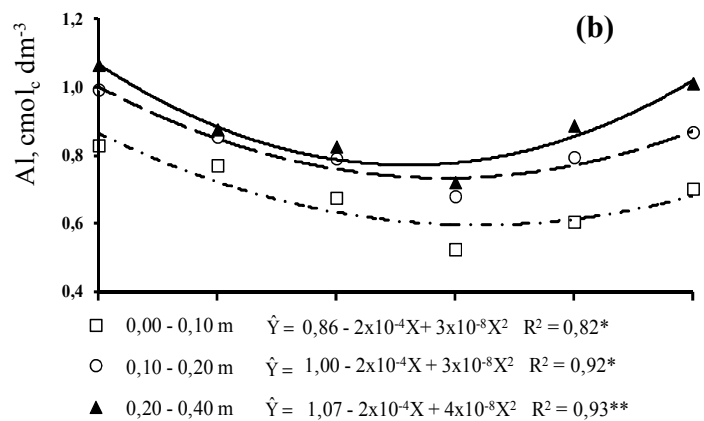

(d)

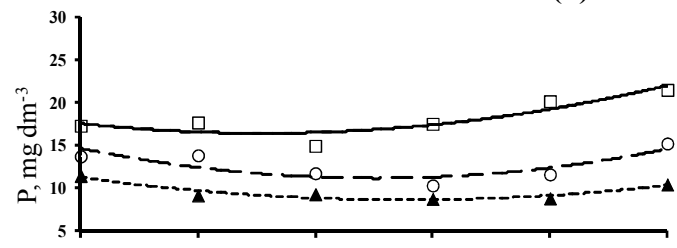

마이 $0,00-0,10 m \quad y=17,539-0,0015 X+5 x 10^{-7} X^{2} R^{2}=0,8173$

○ $0,10-0,20 m \quad y=14,63-0,0028 X+6 \times 10^{-7} X^{2} R^{2}=0,6959$

A $0,20-0,40 m \quad y=11,241-0,0019 X+3 \times 10^{-7} X^{2} R^{2}=0,8798$

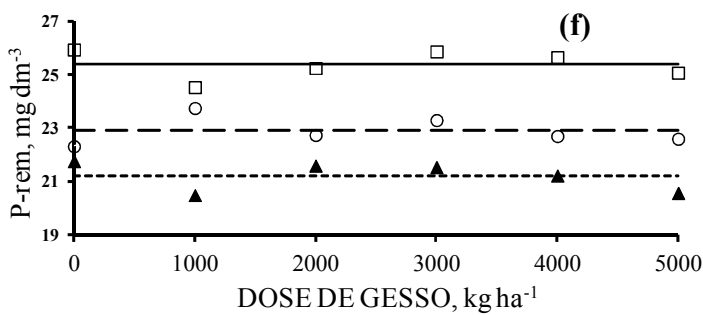

$\square \quad 0,00-0,10 \mathrm{~m} \quad \hat{\mathrm{Y}}=\overline{\mathrm{Y}}=25,40$

O $0,10-0,20 \mathrm{~m} \quad \hat{\mathrm{Y}}=\overline{\mathrm{Y}}=22,91$

A $0,20-0,40 \mathrm{~m} \quad \hat{\mathrm{Y}}=\overline{\mathrm{Y}}=21,20$

Fonte: Elaboração dos autores. 
O uso de $2500 \mathrm{~kg} \mathrm{ha}^{-1}$ de gesso proporcionou ponto de mínimo teor de $\mathrm{Al}$ trocável 12 meses após aplicação em Latossolo Vermelho eutroférrico de textura muito argilosa na profundidade de $0-0,10$ $\mathrm{m}$ e com $3300 \mathrm{~kg} \mathrm{ha}^{-1}$ na profundidade de 0,10 0,20 m e 0,20-0,40 m (Figura $2 \mathrm{a}$ e 2b), condizendo com Souza, Lobato e Rein (1996). Desta forma, além de ser tóxico às plantas, $\mathrm{o} \mathrm{Al}^{3+}$ pode interferir na disponibilidade de fosfato no solo, formando fosfatos de alumínio de baixa solubilidade em solos ácidos (VIVIANI et al., 2010), fato também constatado por Zambrosi, Alleoni e Caires (2007), elevando o P ligado ao Al com a aplicação de doses até $9000 \mathrm{~kg} \mathrm{ha}^{-1}$.

Posteriormente, com doses mais elevadas há aumento tanto do Al quanto do P no solo (Figuras 2a, 2b, 2c e 2d). Segundo Raij (2008), o sulfato de cálcio (gesso) tem uma concentração máxima limitada por sua solubilidade e quando isto ocorre implica em menor remoção do $\mathrm{Al}^{3+}$, limitando a atuação do gesso na redução do teor do $\mathrm{Al}^{+3}$ no solo em doses elevadas. Nestas doses, também pode ocorrer trocas iônicas de $\mathrm{Al}^{3+}$ por $\mathrm{Ca}^{2+}$, deslocando $\mathrm{Al}^{3+}$ para a solução, o qual pode ser imobilizado pelo $\mathrm{SO}_{4}^{2-}$ (PAVAN, 1986), carbono orgânico nas camadas superficiais entre $0-0,20 \mathrm{~m}$ e pelo flúor na camada subsuperficial entre 0,20-0,40 m (ZAMBROSI; ALLEONI; CAIRES, 2007).

A aplicação de gesso implicou em ajuste de regressão quadrática no teor de $\mathrm{Al}$ trocável no solo, com ponto mínimo na dose de $2500 \mathrm{~kg} \mathrm{ha}^{-1}$ na profundidade de 0,20-0,40 m (Figura 2a e 2b). A atuação da calagem efetuada anteriormente à instalação do experimento pode ter proporcionado condições para a atuação diferenciada do gesso no perfil do solo, condizendo com a curva quadrática do Al trocável no solo com ponto de mínima em 858 $\mathrm{kg} \mathrm{ha}^{-1}$, observado por Borges (1997) em colunas de PVC com a aplicação de gesso até $2000 \mathrm{~kg} \mathrm{ha}^{-1}$, após calagem em Latossolo Vermelho Escuro com 0,85 $\mathrm{cmol}_{\mathrm{c}} \mathrm{dm}^{-3}$ de $\mathrm{Al}^{+3}$ e $4,10 \%$ de saturação por bases. Por outro lado, segundo os autores, a aplicação de gesso sem realização de calagem proporcionou redução linear do teor de $\mathrm{Al}$ trocável.

\section{Enxofre disponivel}

A adição de gesso acrescentou enxofre no solo nas camadas superficiais de $0-0,10$ e 0,10 $0,20 \mathrm{~m}$, e na camada subsuperficial de 0,20-0,40 $\mathrm{m}$ logo aos seis meses (Tabela 2), demonstrando alta solubilidade do gesso quando comparado ao calcário. Estes resultados condizem com os encontrados por Nogueira e Melo (2003), mostrando que o máximo de $\mathrm{SO}_{4}^{2-}$ disponível no solo ocorre aos 21 dias após uso do gesso, principalmente carregado inicialmente pela água da precipitação pluvial (ZAMBROSI; ALLEONI; CAIRES, 2007). Todavia, no caso de calagens elevadas, o aumento do $\mathrm{pH}$ provoca a redução da adsorção de sulfato, diminuindo portanto o efeito do gesso nas camadas superficiais, que é "empurrado" perfil abaixo (RAIJ, 2008).

$\mathrm{O}$ acréscimo de enxofre na camada de 0-0,10 m tanto aos seis meses quanto 12 meses após a aplicação do gesso (Tabela 2) evidenciou que solo com textura muito argilosa apresenta alta capacidade de adsorção de fosfato e sulfato (P-rem médio-baixo). Visto que em solos corrigidos com fósforo também há tendência em reduzir a adsorção de enxofre nas camadas superficiais do solo (ALVAREZ V. et al., 2000), de forma que otimiza a percolação de enxofre no perfil do solo. Conforme Malavolta (1992), a percolação de enxofre pode ser elevada e mais rápida quanto menor for a adsorção de enxofre na argila; fato também observado por Borges (1997) em experimento realizado com gesso em Latossolo Vermelho Escuro no qual identificaram tendência em lixiviar mais $\mathrm{S}$ em solos com menor adsorção de $\mathrm{S}$ nas camadas superficiais. 
Tabela 2. Equações de regressão e coeficientes de determinação para as variáveis analisadas em função das doses de gesso nas profundidades de 0-0,10, 0,10-0,20 e 0,20-0,40 m e a produtividade das culturas de soja e trigo, em Latossolo Vermelho eutroférrico de textura argilosa com presença de Al.

\begin{tabular}{|c|c|c|c|c|c|}
\hline Variável & Unidade & Época & Profundidade $(\mathrm{m})$ & Equação & $\mathrm{R}^{2}$ \\
\hline \multirow[t]{6}{*}{$\mathrm{S}$} & $\mathrm{mg} \mathrm{dm^{-3 }}$ & $2006-6$ meses & $0,00-0,10$ & $\hat{\mathrm{Y}}=8,00+2,37 \times 10^{-2} \mathrm{X}$ & $0,93 * *$ \\
\hline & & & $0,10-0,20$ & $\hat{Y}=16,51+2,7 \times 10^{-2} X$ & $0,97 * *$ \\
\hline & & & $0,20-0,40$ & $\hat{Y}=26,14+2,4 \times 10^{-2} X$ & $0,98 * *$ \\
\hline & & $2007-12$ meses & $0,00-0,10$ & $\hat{\mathrm{Y}}=5,48+7,2 \times 10^{-3} \mathrm{X}$ & $0,90 * *$ \\
\hline & & & $0,10-0,20$ & $\hat{\mathrm{Y}}=12,87+9 \times 10^{-3} \mathrm{X}$ & $0,96^{* *}$ \\
\hline & & & $0,20-0,40$ & $\hat{Y}=19,45+1,2 \times 10^{-2} X$ & $0,97 * *$ \\
\hline Produtividade & Unidade & & & & \\
\hline Trigo & $\mathrm{kg} \mathrm{ha}^{-1}$ & & & $\hat{Y}=1368+0,07 X$ & $0,70^{*}$ \\
\hline Soja & $\mathrm{kg} \mathrm{ha}^{-1}$ & & & $\hat{\mathrm{Y}}=\overline{\mathrm{Y}}=3624$ & \\
\hline
\end{tabular}

Fonte: Elaboração dos autores.

A percolação de enxofre encontrada (Tabela 2) está relacionada às características do solo (Tabela 1). As cargas elétricas negativas na superfície das partículas de argila e maior teor de matéria orgânica (MO), responsáveis pela troca de cátions, tem menor capacidade de retenção de sulfato, portanto, repele o ânion (RAIJ, 2008), sendo menos retido na camada superficial, em adição, os óxidos hidratados de ferro e alumínio tem elevada capacidade de adsorção de fosfatos e, com menor intensidade, de sulfato. O maior teor de $\mathrm{MO}$ e menor teor de enxofre encontrados na camada superficial, demonstra que é mais eletronegativa, por outro lado, a redução do teor de MO na camada subsuperficial e maior teor de enxofre, evidencia que é mais eletropositiva (Tabela 1).

As diferenças nas características químicas do solo atreladas à aplicação antecipada de calagem proporcionaram condições mais favoráveis a descida do gesso no perfil do solo, detectado pelo teor de enxofre (Tabela 2). Tal fato foi verificado por Wadt (2000) ao estudar processos envolvendo o sulfato em Latossolo Vermelho-Amarelo, argiloso em reações de adsorção, precipitação ou solubilização, constataram a necessidade de considerar a interação da matéria orgânica com os colóides do solo. Com o predomínio de superfícies com potencial eletropositivo, o sulfato tende a ser preferencialmente adsorvido por estas superfícies.
Havendo predomínio de superfícies com potencial eletronegativo e elevados teores de alumínio trocável, a principal reação do sulfato passa a ser de precipitação com o alumínio, mostrando que o efeito do gesso nas propriedades químicas do solo depende fundamentalmente das características eletroquímicas do solo. Todo este contexto caracteriza a condição favorável a percolação de $\mathrm{SO}_{4}^{-2}$ no perfil do solo e ficar retido nas camadas subsuperficiais, as quais apresentam mais óxidos hidratados de ferro e alumínio.

\section{Fósforo disponível}

A aplicação de gesso a partir da dose de $1500 \mathrm{~kg}$ $\mathrm{ha}^{-1}$ em Latossolo Vermelho eutroférrico de textura muito argilosa proporcionou elevação do teor de $\mathrm{P}$ disponível na profundidade de $0-0,10 \mathrm{~m}$, a partir de $2333 \mathrm{~kg} \mathrm{ha}^{-1}$ na profundidade de $0,10-0,20 \mathrm{~m}$ e a partir de $3166 \mathrm{~kg} \mathrm{ha}^{-1}$ na profundidade de $0,20-0,40$ $\mathrm{m}$ atrelado a elevação do $\mathrm{Al}^{+3}$ a partir da dose de $3300 \mathrm{~kg} \mathrm{ha}^{-1}$ (Figura 2c e 2d), de forma que pode estar ocorrendo três processos concomitantemente no solo.

Primeiramente, Zambrosi, Alleoni e Caires (2007) relataram em experimento em Latossolo Vermelho distrófico textura argilosa, sob sistema plantio direto com a aplicação de gesso, a 
ocorrência da interação de formas químicas de $\mathrm{P}$ com alumínio. Estes autores constataram que o P-Al na camada 0-0,05 $\mathrm{m}$ apresentou em menor proporção na ausência de gesso, apresentando $71,4 \% \pm 19,31$ como $\mathrm{H}_{2} \mathrm{PO}_{4}^{-}$e $18,6 \% \pm 5,70$ como $\mathrm{Al}_{-} \mathrm{H}_{\mathrm{x}} \mathrm{PO}_{4}{ }^{\mathrm{x}}$. Nesta camada, com o uso de 3000 $\mathrm{kg} \mathrm{ha}^{-1}$ de gesso ocorre aumento de P-Al no solo apresentando $38,2 \% \pm 44,10$ como $\mathrm{H}_{2} \mathrm{PO}_{4}^{-}$e $59,80 \%$ $\pm 34,0$ como Al- $\mathrm{H}_{\mathrm{x}} \mathrm{PO}_{4}{ }^{\mathrm{x}}$ e com o uso de $9000 \mathrm{~kg} \mathrm{ha}^{-1}$ de gesso ocorreu incremento maior de P-Al no solo apresentando 54,2\% $\pm 17,10$ como $\mathrm{H}_{2} \mathrm{PO}_{4}^{-}$e 42,60\% $\pm 19,7$ como $\mathrm{Al}-\mathrm{H}_{\mathrm{x}} \mathrm{PO}_{4}{ }^{\mathrm{x}}$ e consequentemente reduziu os teores de P na forma aniônica. Assim, a redução do P disponível pode ter ocorrido nas doses menores de gesso, pois com o incremento do $\mathrm{CaSO}_{4}{ }^{0}$ pelo uso do gesso, evidenciado pela elevação do teor de $\mathrm{Ca}$; assim desloca o Al para a solução e aumenta o P-Al, diminuindo o P solúvel (ZAMBROSI; ALLEONI; CAIRES, 2007).

De forma análoga, Zambrosi, Alleoni e Caires (2008) utilizando a aplicação de calcário dolomítico em Latossolo Vermelho distrófico textura argilosa, encontraram fósforo nas formas livres $\left(\mathrm{H}_{2} \mathrm{PO}_{4}^{-}\right.$ e $\mathrm{HPO}_{4}{ }^{2-}$ ) e também interagindo com alumínio (par iônico $\mathrm{Al}-\mathrm{H}_{\mathrm{x}} \mathrm{PO}_{4}{ }^{\mathrm{x}}$ ), sobretudo até $0,10 \mathrm{~m}$ de profundidade, corraborando com a especiação química de $\mathrm{P}$ evidenciada por Zambrosi, Alleoni e Caires (2007). No entanto, segundo os mesmos autores, em doses elevadas de gesso ocorreu redução das formas de $\mathrm{P}$-Al nas camadas de $0-0,05$ e $0,05-0,10 \mathrm{~m}$ de profundidade, e ressaltaram que nas camadas subjacentes as doses de gesso não interferiram na especiação química do fosfato. Não obstante, segundo Zambrosi, Alleoni e Caires (2007), nas camadas superficiais ocorre maior quantidade de Al ligado a carbono enquanto nas camadas subsuperficiais ocorre mais espécie de Al ligado a F (flúor), reduzindo o Al ligado ao carbono orgânico dissolvido.

A mobilidade do gesso na profundidade de 0,200,40 m também pode implicar em maior ligação de $\mathrm{P}-\mathrm{Al}$ no solo e com as doses mais elevadas, ocorrer aumento na concentração de $\mathrm{S}$ e formação do par iônico $\mathrm{AlSO}_{4}^{+}$, reduzindo as formas de P-Al e com isto ocorre incremento de $\mathrm{P}$ no solo em doses mais elevadas na camada superficial.

E, por último, a aplicação de gesso proporcionou elevação do teor de $\mathrm{P}$ disponível na profundidade de $0-0,10 \mathrm{~m}, 0,10-0,20 \mathrm{~m}$ e $0,20-0,40 \mathrm{~m}$, ao passo que isto também pode ter relação com a substituição de $\mathrm{H}_{2} \mathrm{PO}_{4}^{-}$por $\mathrm{SO}_{4}^{-2}$. Com o aumento das doses de gesso, pode ter elevado a troca de $\mathrm{SO}_{4}^{-2}$ por $\mathrm{H}_{2} \mathrm{PO}_{4}^{-}$ disponibilizando $\mathrm{P}$, detectado com incremento de fósforo disponível (Figura 2c e 2d). $\mathrm{O} \mathrm{CaSO}_{4}$ que é adicionado como gesso, pode sofrer dissociação e formar $\mathrm{CaPO}_{4}$, devido a liberação de Ca na solução. No entanto, o $\mathrm{PO}_{4}^{-3}$ é um ânion de baixa percolação no perfil do solo, resultando em menor acréscimo do teor de P por percolação no perfil do solo explorado pelas raízes das culturas de trigo e soja.

$\mathrm{O}$ incremento no teor de $\mathrm{P}$ com o uso de gesso, também foi verificado por Vital et al. (2005) que estudou a adição de $\mathrm{P}$ através do gesso, em solo com teor de $12,9 \mathrm{mg} \mathrm{kg}^{-1}$ de P. De forma que a elevação da concentração de sulfato no solo, nas maiores doses de gesso proporcionaram maior dessorção do fósforo, mostrando que a aplicação de gesso em solo salino-sódico favorece alguns atributos químicos do solo como o teor de fósforo. Os autores recomendaram a aplicação de gesso em solos salino-sódico que exigem adubação fosfatada como alternativa para elevar o teor de fósforo disponível.

A elevada capacidade de retenção de fosfato do solo em estudo (Figura 2e e 2f) ocorre principalmente por apresentar maior capacidade tampão de $\mathrm{P}$, a qual pode proporcionar elevada competição entre o solo e a planta pelo P aplicado como fertilizante (NOVAIS; SMYTH, 1999), fato que pode estar inibindo o incremento do P disponível nas menores doses de gesso. Solos ricos em óxidos de ferro e de alumínio, como o solo argiloso avaliado, apresentam elevada adsorção de P (RESENDE et al., 2007), exigindo elevada adubação desse nutriente para se ter uma disponibilidade adequada às plantas. Em razão da elevada adsorção de $\mathrm{P}$, principalmente em solos 
oxídicos, algumas práticas de manejo do solo têm sido adotadas no sentido de reduzir sua adsorção e aumentar a eficiência dos fertilizantes fosfatados. Entre elas, destaca-se o incremento de matéria orgânica ao solo pela palhada através do sistema de plantio direto e através do uso de fertilizantes orgânicos, uma vez que os compostos orgânicos podem competir pelos mesmos sítios de adsorção de P (ANDRADE et al., 2003). Nesse contexto, ressalta-se que a adsorção de fósforo por compostos orgânicos é maior no horizontes A que no horizontes $\mathrm{B}$, pois no horizontes $\mathrm{B}$ possui maior teor de óxidos de ferro e argilominerais e no horizonte A têm maior teor de matéria orgânica (BENKE; MERMUT; SHARIATMADARI, 1999).

A elevação do teor de $\mathrm{P}$ nas doses elevadas de gesso também foi detectado por Caires et al. (2003), onde observaram aumento linear dos teores de $\mathrm{P}$ (Mehlich-1) na camada superficial do solo de 0-0,05 m, nos três anos de cultivo avaliados. Caires et al. (2006) verificaram efeito significativo com incremento linear no teor de $\mathrm{P}$ em grãos de soja com a aplicação de 3000 a $9000 \mathrm{~kg} \mathrm{ha}^{-1}$ gesso, demonstrando que as modificações químicas no solo resultaram em incremento na produtividade da cultura da soja.

A modificação da disponibilidade de $\mathrm{P}$ observada também foi identificada por Caires et al. (2011) com a aplicação de gesso em um Latossolo Vermelho argiloso de alta fertilidade e baixa acidez sob plantio direto, com incremento da produção de milho e soja, com aumento na concentração de $\mathrm{P}$ na camada superficial de 0-0,10 m. Conforme Caires et al. (2011), o gesso, disponível em grande parte do mundo como subproduto da indústria de ácido fosfórico contém pequenas concentrações de fósforo $(\mathrm{P})$, sendo importante para a nutrição das plantas com aplicação em doses elevadas (SUMNER et al., 1986). Doses de gesso aplicados no solo podem fornecer $\mathrm{P}$ na camada superficial com aumento do $\mathrm{P}$ disponível na solução do solo (DIAS, 1992; CAIRES et al., 2011). A elevação de $\mathrm{P}$ na camada superficial do solo com a aplicação de gesso em Latossolo Vermelho-Escuro proporcionou incremento da produção de matéria verde, matéria seca e altura de plantas de capim-tanzânia (CUSTÓDIO et al., 2005).

Assim, a utilização de gesso como fonte de P (Figura 2c e 2d) se torna importante, ao considerar o aproveitamento total do $\mathrm{P}$ das rochas, pois a utilização gesso em alguns locais incrementa o teor de P ao solo (SUMNER et al., 1986; DIAS, 1992; CUSTÓDIO et al., 2005; CAIRES et al., 2011). De maneira que a possibilidade de utilização de doses de gesso como fonte auxiliar de P pode ser considerada, visto que, segundo Quevedo e Paganini (2011), o gerenciamento do aporte de $\mathrm{P}$ nos fertilizantes na atividade agrícola auxilia na preservação de um nutriente que não pode ser substituído nos processos biológicos por nenhum outro elemento naturalmente disponível ou sintetizado pelo homem, e cujas fontes, são finitas.

\section{Fósforo remanescente}

Em relação ao teor de $\mathrm{P}$ remanescente (P-rem), não ocorreu alteração com a aplicação das doses crescentes de gesso no solo (Figura 2e e 2f), de forma que o potencial de adsorção de fosfato nos sítios de troca continua inalterado, que segundo Valladares, Pereira e Anjos (2003), solos de textura mais argilosa apresentam elevada capacidade de adsorção de fósforo, e ao considerar o trabalho realizado por Broggi et al. (2011), no qual as características que refletiram o fator capacidade de $\mathrm{P}$ (FCP) foram o $\mathrm{P}$ remanescente (P-rem) e a capacidade máxima de adsorção de $\mathrm{P}$ (CMAP). De maneira que, em trabalho conduzido por Bastos et al. (2010) também demonstraram a possibilidade de utilizar o P-rem correlacionando com a CMAP para recomendar adubação para a cultura de milho, pois em Neossolo Flúvico a adubação fosfatada com dose correspondente a 30\% da CMAP proporcionou incremento do teor foliar de P. Desta forma, a ausência de interferência do gesso no P-rem permite utilizar a recomendação de adubação fosfatada na 
cultura de milho baseada no P-rem, conforme Bastos et al. (2010).

Desta forma, o P-rem determinado após uso de gesso é uma variável confiável para caracterizar a adsorção de $\mathrm{P}$ nos solos, além da praticidade de determinação. Segundo Corrêa, Nascimento e Rocha (2011), ao realizar a avaliação de diversos solos brasileiros encontrou correlação de CMAP e argila $(\mathrm{r}=0,92)$ e P-rem $(\mathrm{r}=-0,95)$. Da mesma forma, Farias et al. (2009) observaram correlação de -0,95 entre CMAP e P-rem para Vertissolo Háplico, ou seja, o P-rem realmente é uma variável indicada para avaliar a capacidade de adsorção de P no solo. A atuação diferenciada do gesso, interferindo no $\mathrm{P}$ disponível (P Mehlich-1) e ausência de interferência na capacidade máxima de adsorção de fosfato, detectável indiretamente pelo P-rem, primariamente está relacionada ao P-rem estar mais interligado com as características mineralógicas e granulométricas do solo que o P disponível. Segundo Eberhardt et al. (2008) o P extraído por Mehlich-1 não se correlacionou com o $\mathrm{P}$ da resina, tampouco com as características mineralógicas e granulométricas dos solos, por outro lado o P-rem correlacionou com a mineralogia da fração argila dos Latossolos do Cerrado, destacando-se a gibbsita, abundante nestes solos, e aos óxidos de Fe e de Al livres e amorfos e concluem que o $\mathrm{P}$ disponível no solo depende principalmente do manejo do solo, do sistema de produção e da adubação fosfatada.

Ao avaliar os resultados obtidos com a aplicação do gesso fica evidente a diferença de adsorção de $\mathrm{P}$ nas camadas avaliadas, apresentando menor P-rem nas camadas subsuperficiais. As diferenças existentes entre as camadas $0-0,10,0,10-0,20$ e 0,20 $0,40 \mathrm{~m} \mathrm{pH}, \mathrm{Al}$ trocável e matéria orgânica (Tabela 1) podem afetar a adsorção de $\mathrm{P}$, interferindo no P-rem. Visto que na camada de $0-0,10 \mathrm{~m}$ apresenta maior P-rem, logo apresenta menor capacidade máxima de adsorção de fósforo enquanto que na camada 0,200,40 $\mathrm{m}$ apresenta menor P-rem e consequentemente maior CMAP. Andrade, Fernandes e Faquin (2002) observaram que para diferentes classes de solos como Organossolo Mésico, Gleissolo Melânico, Gleissolo Háplico e Neossolo Flúvico a utilização de resíduos orgânicos de esterco de curral curtido e calcário proporcionaram redução de $\mathrm{Al}$ trocável no solo e aumento do $\mathrm{pH}$, já a aplicação de gesso proporcionou redução do Al trocável, e os três produtos reduziram a adsorção de fósforo nos solos de várzea estudados, obtendo elevação do P-rem. Assim observou a correlação entre P-rem e pH (r $=0,69), \mathrm{Al}^{+3}(\mathrm{r}=-0,78)$ e CMAP $(\mathrm{r}=-0,98)$ e ao analisar o CMAPe P-rem demonstraram que o esterco reduziu a CMAP e elevou o P-rem. Ao contrário, Azevedo et al. (2004) ao avaliar a influência de calcário, gesso e esterco de curral curtido, aplicados em cultivo prévio de feijoeiro em Neossolo Flúvico, Gleissolo Háplico, Gleissolo Melânico e Organossolo Mésico submetidos ao cultivo de arroz e artificialmente drenado verificaram que o gesso e calcário não interferiram na determinação de P-rem, mas a aplicação de esterco de curral aumentou o P-rem, reduzindo a capacidade máxima de adsorção de P. Da mesma forma, a adição de esterco bovino e de calcário, os quais incrementaram os valores de P-rem, reduziram a CMAP, tanto em Neossolo Quartzarênico órtico, Latossolo Vermelho-Amarelo distrófico textura média, Latossolo VermelhoAmarelo distrófico textura argilosa e Latossolo Vermelho distrófico textura muito argilosa (SOUZA; LOBATO; REIN, 2006).

Pelo fato da correlação de P-rem e CMAP ser alta (ALVAREZ V. et al., 2000; BROGGI et al., 2010; VILAR et al., 2010), a manutenção do teor de P-rem demonstra que a CMAP permanece inalterada com a adição de gesso. Sendo assim a alteração dos teores dos nutrientes que ocorre no solo, tanto para o $\mathrm{S}$ disponível, Al trocável e $\mathrm{P}$ disponível provavelmente são provocadas por alterações químicas independentes da capacidade de adsorção de P. A aplicação de gesso também não interferiu no P-rem em trabalho realizado por Fernández et al. (2008) no qual verificaram ausência de reversibilidade de $\mathrm{P}$ não-lábil com a redução microbiana ou química dos solos, não interferindo 
na CMAP detectado pelo P-rem, fato que demonstra a grande estabilidade dessas formas; sendo que a formação de P não-lábil a partir de formas lábeis, adsorvidas aos oxihidróxidos de $\mathrm{Fe}$ e $\mathrm{Al}$, é razão para o baixo efeito residual da fertilização fosfatada em solos tropicais.

A presença de maior valor de P-rem (menor CMAP) na camada superficial em relação às camadas adjacentes, demonstra que é a camada mais explorada do perfil do solo. Tal fato é evidenciado por Costa, Goedert e Souza (2006), os quais detectaram menor valor de P-rem (maior CMAP) em solo sob vegetação natural de cerrado que solo sob sistema de preparo convencional ou sob sistema plantio direto, fato que transcreve a existência de menor capacidade máxima de adsorção de $\mathrm{P}$ nos sistemas de cultivo mecanizados. Em síntese, na camada mais cultivada, como a camada 0-0,10 m apresentou maior P-rem (menor CMAP) enquanto que a camada 0,20-0,40 $\mathrm{m}$ com cultivo menos atuante diretamente apresentou menor P-rem (maior CMAP).

Desta forma, a identificação de maior P-rem na camada superficial também tem estreita relação com o sistema de semeadura direta, devido ao maior acúmulo de palhada na superfície propiciado por este sistema e incremento do teor de matéria orgânica do solo (Tabela 1) e consequentemente reduzida adsorção de fósforo, caracterizando-a com maior P-rem (Figura 2e e 2f). Isto proporciona uma informação importante para a realização de adubação fosfatada, pois ao realizar a aplicação no solo, especificamente na camada superficial em sistema de plantio direto, que possui maior P-rem traz benefícios quanto a eficiência superior da adubação e eficiência no uso de $\mathrm{P}$ do fertilizante pelas plantas. Segundo Pereira et al. (2010), a matéria orgânica é o indicador mais responsivo à interação dos efeitos dos sistemas de manejo e culturas agrícolas avaliadas, visto que em sistemas sem revolvimento do solo o aumento nos teores de matéria orgânica nas camadas superficiais podem reduzir a adsorção de fósforo ao solo.
Conforme Santos, Neves e Novais (2008) podese utilizar modelagem para a recomendação de corretivos e fertilizantes, e para o enxofre pode-se considerar o P-rem como a variável principal na variação das doses recomendadas, uma vez que esta variável reflete a capacidade tampão do solo. Isso se justifica por ser o enxofre um nutriente que tem sua disponibilidade influenciada pelo poder-tampão do solo, assim como ocorre com o fósforo, o qual pode ser medido indiretamente pelo P-rem. Desta forma, ao considerar o P-rem para recomendar a aplicação enxofre, conforme metodologia utilizada por Alvarez V. et al. (2000), na determinação da necessidade de gesso e utilizado também por Santos, Neves e Novais (2008) no uso de modelagem para recomendar adubação é oportuno ter conhecimento de aplicações anteriores de gesso na área para não realizar aplicação excessiva de gesso, visto que, a aplicação deste subproduto da indústria de fertilizante no solo não interfere no valor do P-rem (Figura 2e e 2f).

\section{Produtividade das culturas}

Houve incremento linear para a produtividade da cultura do trigo em função das doses de gesso (Tabela 2) com a utilização da variedade CD 104, sensível ao alumínio trocável, de fato o $\mathrm{Al}^{+3}$ no solo após a cultura do trigo na ausência de aplicação de gesso foi de $0,93 \mathrm{cmol}_{\mathrm{c}} \mathrm{dm}^{-3}$ na profundidade de $0,20-0,40$ $\mathrm{m}$ (Figura 2a). Isto demonstra a interferência da aplicação de gesso, conforme observado por Pavan, Bingham e Pratt (1984) em solos com toxidez por $\mathrm{Al}^{+3}$, fato também detectada por Caires et al. (2002) na cultura do trigo em solo com teor de $0,8 \mathrm{cmol}_{\mathrm{c}}$ $\mathrm{dm}^{-3} \mathrm{Al}^{3+}$, tóxico às plantas.

No entanto, a cultura da soja não sofreu interferência significativa da adição de gesso em sistema de semeadura direta (Tabela 2). Tal fato pode estar relacionado às raízes da cultura da soja, que ao fixarem $\mathrm{N}_{2}$ deixam de absorver $\mathrm{N}_{-} \mathrm{NO}_{3}{ }^{-} \mathrm{e}$ liberarem $\mathrm{OH}^{-}$e sim, exsudarem $\mathrm{H}^{+}$em maior proporção ao absorverem cátions, acidificando o 
solo (MARSCHNER, 1995), ou seja, a cultura da soja transforma sua rizosfera, acidificando-a devido as suas relações com o Bradyrhizobium. Neste momento, o teor de $\mathrm{Al}^{+3}$ encontrado no solo pode não ter sido tóxico para a cultura, atrelado também a condição de que a variedade CD 214RR ser tolerante ao alumínio.

\section{Conclusões}

A aplicação de gesso a partir da dose de $1500 \mathrm{~kg}$ $\mathrm{ha}^{-1}$ em Latossolo Vermelho eutroférrico de textura muito argilosa proporciona elevação do teor de $\mathrm{P}$ disponível na profundidade de $0-0,10 \mathrm{~m}$, a partir de $2333 \mathrm{~kg} \mathrm{ha}^{-1}$ na profundidade de $0,10-0,20 \mathrm{~m}$ e a partir de $3166 \mathrm{~kg} \mathrm{ha}^{-1}$ na profundidade de 0,20-0,40 m.

O uso de gesso na dose de 1000 a $5000 \mathrm{~kg} \mathrm{ha}^{-1}$ não interfere no valor do P remanescente até $0,40 \mathrm{~m}$ de profundidade, sendo oportuno atentar sobre aplicações anteriores ao recomendar gesso pelo P-rem.

$\mathrm{O}$ uso de $2500 \mathrm{~kg} \mathrm{ha}^{-1}$ de gesso proporciona ponto de mínimo teor de $\mathrm{Al}$ trocável 12 meses após aplicação em Latossolo Vermelho eutroférrico de textura muito argilosa na profundidade de $0-0,10 \mathrm{~m}$ e com $3300 \mathrm{~kg} \mathrm{ha}^{-1}$ na profundidade de $0,10-0,20 \mathrm{~m}$ e $0,20-0,40 \mathrm{~m}$.

Um ano após a aplicação de doses de gesso de 1000 a $5000 \mathrm{~kg} \mathrm{ha}^{-1} \mathrm{o}$ teor de $\mathrm{S}$ é elevado nas profundidades do solo de $0-0,10 \mathrm{~m}, 0,10-0,20 \mathrm{~m}$ e 0,20-0,40 m.

O uso do gesso aumenta a produtividade de trigo variedade CD 104, mas não influencia a produtividade da soja variedade CD 214RR.

\section{Agradecimentos}

À Coordenadoria de Aperfeiçoamento de Pessoal de Ensino Superior (CAPES) e Fundação Araucária de Apoio ao Desenvolvimento Científico e Tecnológico do Paraná (FUNDAÇÃO ARAUCÁRIA), pela concessão de bolsas de estudo.

\section{Referências}

ASSOCIAÇÃO BRASILEIRA DAS INDÚSTRIAS DE ÓLEOS VEGETAIS - ABIOVE. Tributação na indústria de óleos vegetais. Fabio Trigueirinho, Secretário Geral. Goiânia, 2011. Disponível em: <http://www.abiove.com. br/palestras_br.html>. Acesso em: 28 jun. 2011.

ALLEONI, L. R. F.; CAMBRI, M. A.; CAIRES, E. F. Atributos químicos de um Latossolo de cerrado sob plantio direto, de acordo com doses e formas de aplicação de calcário. Revista Brasileira de Ciências do Solo, Viçosa, v. 29, n. 6, p. 923-934, 2005.

ALVAREZ V., V. H.; NOVAIS, R. F.; DIAS, L. E.; OLIVEIRA, J. A. Determinação e uso do fósforo remanescente. Boletim Informativo, Viçosa, v. 25, p. $27-$ 33, 2000.

ANDRADE, A. T.; FERNANDES, L. A.; FAQUIN, V. Organic residue, limestone, gypsum, and phosphorous adsorption by lowland soils. Scientia Agricola, Piracicaba, v. 59, n. 2, p. 349-355, 2002.

ANDRADE, F. V.; MENDONÇA, E. S.; ALVAREZ, V. H.; NOVAIS, R. F. Adição de ácidos orgânicos e húmicos em Latossolos e adsorção de fosfato. Revista Brasileira de Ciências do Solo, Viçosa, v. 27, n. 6, p. 1003-1011, 2003.

ARAÚJO, F. F.; TIRITAN, C. S.; PEREIRA, H. M.; CAETANO JÚNIOR, O. Desenvolvimento do milho e fertilidade do solo após aplicação de lodo de curtume e fosforita. Revista Brasileira de Engenharia Agrícola e Ambiental, Campina Grande, v. 12, n. 5, p. 507-511, 2008.

AZEVEDO, W. R.; FAQUIN, V.; FERNANDES, L. A.; OLIVEIRA JÚNIOR, A. C. Disponibilidade de fósforo para o arroz inundado sob efeito residual de calcário, gesso e esterco de curral aplicados na cultura do feijão. Revista Brasileira de Ciência do Solo, Viçosa, v. 28, n. 6, p. 995-1004, 2004.

BASTOS, A. L.; COSTA, J. P. V.; SILVA, I. F.; RAPOSO, R. W. C.; OLIVEIRA, F. A.; ALBUQUERQUE, A. W. Resposta do milho a doses de fósforo. Revista Brasileira de Engenharia Agrícola e Ambiental, Campina Grande, v. 14, n. 5, p. 485-491, 2010.

BENKE, M. B.; MERMUT, A. R.; SHARIATMADARI, $\mathrm{H}$. Retention of dissolved organic carbon from vinasse by a tropical soil, kaolinite, and Fe-oxides. Geoderma, Amsterdam, v. 91, n. 1-2, p. 47-63, 1999.

BILIBIO, W. D.; CORRÊA, G. F.; BORGES, E. N. Atributos fisicos e químicos de um latossolo, sob diferentes sistemas de cultivo. Ciência e Agrotecnologia, Lavras, v. 34, n. 4, p. 817-822, 2010. 
BORGES, E. N. Efeito de calcário e gesso nos teores de cálcio e alumínio da camada compactada em Latossolo Vermelho-Escuro. Pesquisa Agropecuária Brasileira, Brasília, v. 32, p. 107-114, 1997.

BROGGI, F.; OLIVEIRA, A. C.; FREIRE, F. J.; FREIRE, M. B. G. S.; NASCIMENTO, C. W. A. Fator capacidade de fósforo em solos de Pernambuco mineralogicamente diferentes e influência do $\mathrm{pH}$ na capacidade máxima de adsorção. Ciência e Agrotecnologia, Lavras, v. 35, n. 1, p. 77-83, 2011.

BROGGI, F.; OLIVEIRA, A. C.; FREIRE, F. J.; FREIRE, M. B. G. S.; NASCIMENTO, C. W. A. Adsorption and chemical extraction of phosphorus as a function of soil incubation time. Revista Brasileira de Engenharia Agrícola e Ambiental, Campina Grande, v. 14, n. 1, p. 32-38, 2010.

CAIRES, E. F.; FELDHAUS, I. C.; BARTH, G.; GARBUIO, F. J. Lime na gypsum application on the wheat crop. Scientia Agricola, Piracicaba, v. 59, n. 2, p. 357-364, 2002.

CAIRES, E. F.; BLUM, J.; BARTH, G.; GARBUIO, F. J.; KUSMAN, M. T. Alterações químicas do solo e resposta da soja ao calcário e gesso aplicados na implantação do sistema plantio direto. Revista Brasileira de Ciências do Solo, Viçosa, v. 27, n. 2, p. 275-286, 2003.

CAIRES, E. F.; GARBUIO, F. J.; ALLEONI, L. R. F.; CAMBRI, M. A. Calagem superficial e cobertura de aveia preta antecedendo os cultivos de milho e soja em sistema de plantio direto. Revista Brasileira de Ciências do Solo, Viçosa, v. 30, n. 1, p. 87-98, 2006.

CAIRES, E. F.; MASCHIETTO, E. H.; GARBUIO, F. J.; CHURKA, S.; JORIS, H. A. W. Surface application of gypsum in low acidic Oxisol under no-till cropping system. Scientia Agricola, Piracicaba, v. 68, n. 2, p. 209216, 2011.

COMPANHIA NACIONAL DE ABASTECIMENTO CONAB - Acompanhamento da safra brasileira: grãos, nono levantamento junho 2011. Companhia Nacional de Abastecimento, Brasília: Conab, 2011. Disponível em: <http://www.conab.gov.br/OlalaCMS/uploads/ arquivos/11_06_09_08_50_47_graos___boletim_ junho-2011.pdf $>$. Acesso em: 28 jun. 2011.

CORRÊA, R. M.; NASCIMENTO, C. W. A.; ROCHA, A. T. Adsorção de fósforo em dez solos do Estado de Pernambuco e suas relações com parâmetros físicos e químicos. Acta Scientiarum Agronomy, Maringá, v. 33, n. 1, p. 153-159, 2011.

COstA, E. A.; GOEDERT, W. J.; SOUZA, D. M. G. Qualidade de solo submetido a sistemas de cultivo com preparo convencional e plantio direto. Pesquisa Agropecuária Brasileira, Brasília, v. 41, n. 7, p. 1185 1191, 2006.

CUSTÓDIO, D. P.; OLIVEIRA, I. P.; COSTA, K. A. P.; SANTOS, R. S. M.; FARIA, E. D. Avaliação de gesso no desenvolvimento e produção do capim-tanzânia. Ciência Animal Brasileira, Goiânia, v. 6, n. 1, p. 27-34, 2005.

DIAS, L. E. Uso de gesso como insumo agrícola. Seropédica: Embrapa/Centro Nacional de Pesquisa de Biologia-CNPBS. 1992. 6 p. (Comunicado técnico, 7).

EBERHARDT, D. N.; VENDRAME, P. R. S.; BECQUER, T.; GUIMARÃES, M. F. Influência da granulometria e da mineralogia sobre a retenção do fósforo em latossolos sob pastagens no cerrado. Revista Brasileira de Ciências do Solo, Viçosa, v. 32, n. 3, p. 1009-1016, 2008.

EMPRESA BRASILEIRA DE PESQUISA AGROPECUÁRIA - EMBRAPA. Centro de Pesquisa de Solos. Manual de métodos de análise do solo. Rio de Janeiro: Embrapa, 1997. 212 p.

. Centro Nacional de Pesquisa de Solos. Sistema brasileiro de classificação de solos. Brasília: Embrapa Produção de Informação, 2006. 306 p.

. Manual de análises químicas de solos, plantas e fertilizantes. Brasília, Embrapa Solos/Embrapa Informática Agropecuária/Embrapa Comunicação para Transferência de Tecnologia, 1999. 370 p.

FARIAS, D. R.; OLIVEIRA, F. H. T.; SANTOS, D.; ARRUDA, J. A.; HOFFMANN, R. B.; NOVAIS, R. T. Fósforo em solos representativos do estado da Paraíba. IIsotermas de adsorção e medidas do fator capacidade de fósforo. Revista Brasileira de Ciências do Solo, Viçosa, v. 33, n. 3, p. 623-632, 2009.

FERNÁNDEZ, I. E.; NOVAIS, R. F.; NUNES, F. N.; KER, J. C. Reversibilidade de fósforo não-lábil em solos submetidos à redução microbiana e química. II - extrações sucessivas do fósforo pela resina de troca aniônica. Revista Brasileira de Ciências do Solo, Viçosa, v. 32, n. 6, p. 2319-2330, 2008.

FRANCHINI, J. C.; GONZALEZ-VILLA, F. J.; MIYAZAWA, M.; PAVAN, M. A. Rapid transformations of plant water soluble organic compounds in relation to cation mobilization in acid Oxisol. Plant and Soil, The Hague, v. 231, n. 1, p. 55-63, 2001.

FRANCHINI, J. C.; HOFFMANN-CAMPO, C. B.; TORRES, E.; MIYAZAWA, M.; PAVAN, M. A. Organic composition of green manures during growth and its effect on cation mobilization in an acid oxisol. Comm. Soil Science and Plant Analysis, Nova York, v. 34, n. 1314, p. 2045-2058, 2003. 
HSU, P. H. Aluminum hydroxides and oxyhydroxides. In: DIXON, J. B.; WEED, S. B. (Ed.). Minerals in soil environments. Madison: Soil Science Society of America, 1989. p. 331-378.

MALAVOLTA, E. O gesso agrícola no ambiente e na nutrição da planta - perguntas e respostas. In: SEMINÁRIO SOBRE O USO DO GESSO NA AGRICULTURA, 2., 1992, Uberaba. Anais... São Paulo: Ed. Nagy, 1992. p. 41-66.

MARSCHNER, H. Mineral nutricion of higher plants. 2. ed. San Diego, Academic Press. 1995. 889 p.

NEIS, L.; PAULINO, H. B.; SOUZA, E. D.; REIS, E. F.; PINTO, F. A. Gesso agrícola e rendimento de grãos de soja na região do sudoeste de Goiás. Revista Brasileira de Ciências do Solo, Viçosa, v. 34, n. 2, p. 409-416, 2010.

NOGUEIRA, M. A.; MELO, W. J. Enxofre disponível para a soja e atividade de arilsulfatase em solo tratado com gesso agrícola. Revista Brasileira de Ciências do Solo, Viçosa, v. 27, n. 4, p. 655-663, 2003.

NOVAIS, R. F.; ALVAREZ V, H.; BARROS, N. F.; FONTES, R. L. F.; CANTARUTTI, R. B.; NEVES, J. C. L. Fertilidade do solo. Viçosa, MG: Sociedade Brasileira de Ciência do Solo, 2007. 1017 p.

NOVAIS, R. F.; SMYTH, T. J. Fósforo em solos e plantas em condições tropicais. Viçosa, MG: UFV, 1999. 399 p.

PAVAN, M. A.; BINGHAM, F. T.; PRATT, P. F. Redistribution of exchangeable calcium, magnesium, and aluminum following lime or gypsum applications to a Brasilian oxisol. Soil Science Society of America Journal, Madison, v. 48, n. 1, p. 33-38, 1984.

PAVAN, M. A. Comportamento do gesso nos solos ácidos das regiões tropicais e subtropicais. Piracicaba: Potafos, 1986. 3 p. (Informações Agronômicas, 35).

PEREIRA, G. M.; LOSS, A.; BEUTLER, S. J.; TORRES, J. L. R. Carbono, matéria orgânica leve e fósforo remanescente em diferentes sistemas de manejo do solo. Pesquisa Agropecuária Brasileira, Brasília, v. 45, n. 5, p. 508-514, 2010.

QUAGGIO, J. A.; van RAIJ, B.; GALLO, P. B.; MASCARENHAS, H. A. A. Respostas da soja à aplicação de calcário e gesso e lixiviação de íons no perfil do solo. Pesquisa Agropecuária Brasileira, Brasília, v. 28, n. 3, p. 375-383, 1993.

QUEVEDO, C. M.; PAGANINI, W. S. Impactos das atividades humanas sobre a dinâmica do fósforo no meio ambiente e seus reflexos na saúde pública. Ciência \& Saúde Coletiva, Rio de Janeiro, v. 6, n. 8, p. 3529-3539, 2011.
RAIJ, B. van. Gesso na agricultura. Campinas: Instituto Agronômico, 2008. 233 p.

RAIJ, B. van; MASCARENHAS, H. A. A.; PEREIRA, J. C. V. N. A.; IGUE, T.; SORDI, G. Efeito de calcário e de gesso para soja cultivada em Latossolo roxo ácido saturado com sulfato. Revista Brasileira de Ciências do Solo, Viçosa, v. 18, n. 2, p. 305-312, 1994.

RESENDE, M.; CURI, N.; REZENDE, S. B.; CORREAA, G. F. Pedologia: base para distinção de ambientes. Lavras: UFLA, 2007.

ROTH, C. H.; PAVAN, M. A.; CHAVES, J. C. D.; MEYER, B.; FREDE, H. G. Efeito das aplicações de calcário e gesso sobre a estabilidade de agregados e infiltrabilidade de água em um Latossolo Roxo cultivado com cafeeiros. Revista Brasileira de Ciências do Solo, Viçosa, v. 10, n. 2, p. 163-166, 1986.

UNIVERSIDADE FEDERAL DE VIÇOSA - UFV. SAEG - Sistema de análises estatísticas e genéticas. Versão 8.0. Viçosa, MG: 1999. (Manual do usuário).

SANTOS, F. C.; NEVES, J. C. L.; NOVAIS, R. F. Modelagem da recomendação de corretivos e fertilizantes para a cultura da soja. Revista Brasileira de Ciências do Solo, Viçosa, v. 32, n. 4, p. 1661-1674, 2008.

SILVA, J. B. C.; NOVAIS, R. F.; SEDIYAMA, C. S. Identificação de genótipos de sorgo tolerantes à toxicidade de alumínio. Revista Brasileira de Ciências do Solo, Viçosa, v. 8, n. 1, p. 77-83, 1984.

SILVA, N. M.; RAIJ, B. van; CARVALHO, L. H. Efeitos do calcário e do gesso nas características químicas do solo e na cultura do algodão. Bragantia, Campinas, v. 56, n. 2, p. 389-401, 1997.

SORATTO, R. P.; CRUSCIOL, C. A. C. Atributos químicos do solo decorrentes da aplicação em superfície de calcário e gesso em sistema plantio direto recémimplantado. Revista Brasileira de Ciências do Solo, Viçosa, v. 32, n. 2, p. 675-688, 2008.

SORATTO, R. P.; CRUSCIOL, C. A. C.; MELLO, F. F. C. Componentes da produção e produtividade de cultivares de arroz e feijão em função de calcário e gesso aplicados na superfície do solo. Bragantia, Campinas, v. 69, n. 4, p. 965-974, 2010.

SOUZA, D. M. G.; LOBATO, E.; REIN, T. A. Uso do gesso agrícola nos solos dos cerrados. Planaltina: EMBRAPA-CPAC, 1996. 20 p. (Circular técnica, 32).

SOUZA, F. R.; ROSA JÚNIOR, E. J.; FIETZ, C. R.; BERGAMIN, A. C.; VENTUROSO, L. R.; ROSA, Y. B. C. J. Atributos físicos e desempenho agronômico da 
cultura da soja em um Latossolo Vermelho distrooférrico submetido a dois sistemas de manejos. Ciência e Agrotecnologia, Lavras, v. 34, n. 6, p. 1357-1364, 2010.

SOUZA, R. F.; FAQUIN, V.; TORRES, P. R. F.; BALIZA, D. P. Calagem e adubação orgânica: influência na adsorção de fósforo em solos. Revista Brasileira de Ciências do Solo, Viçosa, v. 30, n. 6, p. 975-983, 2006.

SUMNER, M. E.; SHAHANDEH, H.; BOUTON, J.; HAMMEL, J. Amelioration of an acid soil profile through deep liming and surface application of gypsum. Soil Science Society of America Journal, v. 50, p. 12541258, 1986.

VALLADARES, G. S.; PEREIRA, M. G.; ANJOS, L. H. C. Adsorção de fósforo em solos de argila de atividade baixa. Bragantia, Campinas, v. 62, n. 1, p. 111-118, 2003.

VILAR, C. C.; COSTA, A. C. S.; HOEPERS, A.; SOUZA JÚNIOR, I. G. Capacidade máxima de adsorção de fósforo relacionada a formas de ferro e alumínio em solos subtropicais. Revista Brasileira de Ciências do Solo, Viçosa, v. 34, n. 4, p. 1059-1068, 2010.
VITAL, A. F.; SANTOS, R. V.; CAVALCANTE, L. F.; SOUTO, J. S. Comportamento de atributos químicos de um solo salino-sódico tratado com gesso e fósforo. Revista Brasileira de Engenharia Agrícola e Ambiental, v. 9, n. 1, p. 30-36, 2005.

VITTI, C. G.; LUZ, P. H. C.; MALAVOLTA, E.; DIAS, A. S.; SERRANO, C. G. E. Uso do gesso em sistemas de produção agrícola. Piracicaba: GAPE, 2008. 104 p.

VIVIANI, C. A.; MARCHETTI, M. E.; VITORINO, A. C. T.; NOVElinO, J. O.; GONÇALVES, M. C. Disponibilidade de fósforo em dois latossolos argilosos e seu acúmulo em plantas de soja, em função do aumento do pH. Ciência e Agrotecnologia, Lavras, v. 34, n. 1, p. 61-67, 2010.

WADT, P. G. S. Alterações eletroquímicas de um Latossolo Vermelho-Amarelo tratado com carbonato e sulfato de cálcio. Scientia Agricola, Piracicaba, v. 57, n. 3, p. 519-524, 2000.

ZAMBROSI, F. C. B.; ALLEONI, L. R. F.; CAIRES, E. F. Aplicação de gesso agrícola e especiação iônica da solução de Latossolo sob sistema plantio direto. Ciência Rural, Santa Maria, v. 37, n. 1, p. 110-117, 2007.

. Liming and ionic speciation of an oxisol under no-till system. Scientia Agricola, Piracicaba, v. 65, n. 2 , p. 190-203, 2008. 